\section{ARTICLE}

Nick Barford

\section{Office for National Statistics}

\section{SUMMARY}

This article explains the developments and revisions to the Workforce Jobs (WFJ) series, released by the Office for National Statistics (ONS) on 14 July 2010 in the Labour Market Statistical Bulletin. The main changes are:

- conversion to Standard Industrial Classification 2007

- redesign and new estimation methods for Short Term Employer Surveys

- benchmarking of Employee Jobs to the Annual Business Inquiry and the removal of discontinuities from previous benchmarking exercises

- revisions to inputs including Public Sector Employment and the Labour Force Survey

- review of seasonal adjustment - changes to WFJ publication tables

\title{
Revisions to Workforce Jobs
}

\section{Introduction}

W orkforce Jobs (WFJ) is a quarterly measure of the number of jobs in the UK and is the preferred measure of the change in jobs by industry. It is a compound source that draws on a range of employer surveys, household surveys and administrative sources. WFJ is the sum of Employee Jobs (EJ) measured primarily by employer surveys, Self-Employment Jobs (SEJ) from the Labour Force Survey (LFS), and Government-Supported Trainees (GST) and Her Majesty's Forces (HMF) from administrative sources (see Annex A). A variety of outputs by industry, region, gender and full/part-time status are produced for a range of publications and users (see Annex B).

A fundamental redevelopment of WFJ sources, classifications, methods and systems has been undertaken. The main changes are:

- conversion to the new Standard Industrial Classification 2007 (SIC 2007) from the start of the industrial breakdown in 1978 Q2

- changes to the sample design, size, allocation and periodicity of the ShortTerm Employer Surveys (STES) from 2010 Q1, used for quarterly GB private sector EJ

- new STES estimation methods and systems from 2008 Q3, including:

- a new ratio estimator, replacing the non-standard 'matched-pairs' method

- changes to the method for apportioning reporting units by their local units

- direct estimation of regional estimates by Government Office Region (GOR), as opposed to conversion from the old Standard Statistical Regional basis (SSR)

- benchmarking Great Britain (GB) quarterly Employee Jobs series to the latest Annual Business Inquiry (ABI1) estimates for 2007 and 2008

- removal of benchmarking discontinuities, including the discontinuity between 2005 Q4 and 2006 Q3 caused by changes to ABI1 sources and methods

- revisions to Public Sector Employment (PSE) inputs, entailing more detailed and wider coverage by industry and region

- revisions to LFS inputs and systems from 1996 Q1 and the use of SEJ and GST estimates by region and industry to produce regional WFJ by industry for the first time

- a new time series system for compiling WFJ, utilising preferred benchmarking and seasonal adjustment methods

- a seasonal adjustment review, with more seasonally adjusted series now available by industry and region

- changes to the published tables

Conversion from SIC 2003 to SIC 2007

The move to SIC 2007 complies with European regulations and has been preannounced by ONS in a series of articles 
(see Hughes et al 2009). This is the first major revision of the classification since 1992 and is the outcome of a series of consultations across Europe since 2002. The move to SIC 2007 has provided the opportunity to implement other improvements to WFJ which are explained in this article.

All WFJ sources and outputs have been converted to SIC 2007, back to the start of the series, the earliest point being 1978 Q2 for GB Employee Jobs. Continuous time series are required for the comparability of estimates over time. Depending on the source and data availability, ONS has used different methods for different time spans, and linked them where possible to maintain comparability over time. These methods include a conversion matrix and domain estimation.

\section{Conversion matrix}

Industry series have been put through a conversion matrix from their respective start dates, the earliest being 1978 Q2 for GB Employee Jobs. This method apportions the SIC 2003 series to SIC 2007 using proportions derived from dual-coded employment data for local units from the Inter-Departmental Business Register (IDBR). The same IDBR proportions, as at April 2009 were applied to the entire length of the series. The IDBR only has dual codes for business on both SIC 2003 and SIC 2007 from the start of 2008, and by April 2009 the new basis has had time to stabilise. This aggregate level method was used by ONS at the last major classification change and is widely used by other National Statistics Institutes.

\section{Domain estimation}

From 2008 Q3 to 2009 Q4, a micro-method was used for estimates that feed from STES. The individual survey responses selected under the original SIC 2003 sample design were re-weighted and re-aggregated to form the estimates for SIC 2007 based domains (domain estimation). This micro method was deemed to give higher quality estimates than the cruder conversion matrix method. It was only applicable from 2008, when businesses were first dual-coded on the IDBR. More specifically this was only applied to STES from 2008 Q3, the latest point at which estimates were available from ABI1. STES estimates are benchmarked to $A B I 1$ and this process provided an inherent method for linking the SIC 2007 series produced by the aggregate and micro methods. The benchmarking process is explained in more detail later in the article.
From 2010 Q1, STES were selected, weighted and aggregated based on new SIC 2007 designs. There are likely to be some discontinuities at this point, particularly for more detailed domains. The effect is difficult to measure and adjust for at this stage. The estimates cannot be linked on the series as there are no overlapping periods selected and produced on both the original and new survey designs. Also, the timing of this change coincides with the annual update of the IDBR (between Q4 and Q1), which causes changes to the classifications, structures and registered employment values of businesses. The survey redesign and the register update both increase the sample rotation, causing further volatility. Potential discontinuities will be assessed and treated if possible once a longer time series is available on the new design. The next section explains the redesign of these surveys in more detail.

\section{Redesign of the Short Term Employer Surveys}

EJ is by far the largest component of WFJ. Most of the EJ data comes from STES, a group of surveys that collect employment and also output information from businesses in Great Britain. The output information feeds the Short Term Output Indicators (Index of Production, Index of Services and Retail Sales Index). Both the employment and output series in turn feed National Accounts and productivity measures.

Until the end of 2009 STES comprised:

- the Monthly Production Inquiry (MPI)

- the Monthly Inquiry in to the Distribution and Service Sector (MIDSS)

- the Quarterly Inquiry in the Distribution and Service Sector (QIDSS)

- the Retail Sales Inquiry (RSI)

MPI collected employment information every month, whereas the other surveys collected employment once a quarter in March (Q1), June (Q2), September (Q3) and December (Q4). For a small number of production industries the MPI collected employment only. QIDSS collected only employment, covering the industries not covered by MPI, MIDSS and RSI (hence QIDSS was also known as 'Gaps'). The employment sample for MIDSS was a subsample of the output sample.

From 2010 Q1 these surveys have been restructured. The Monthly Business Survey (MBS) and the Quarterly Business Survey
(QBS) have replaced MPI, MIDSS and QIDSS. In essence, MPI and MIDSS have been combined to create MBS, and QBS has replaced QIDSS with the inclusion of the MPI employment-only industries and additional industries previously covered by external sources, namely banks, private sector schools and landscape gardening. MBS collects output variables every month and employment variables once a quarter for a sub-sample of businesses. Thus the frequency of the employment information collected from the production sector has reduced from monthly to quarterly in line with all other sectors. RSI has remained a separate survey, although for consistency the questionnaire uses 'MBS' in its title, and similarly to MBS the employment variables are now collected for just a sub-sample of businesses that receive the output questions, giving a further reduction in the overall sample size of STES. These changes are illustrated in Table 1.

Like most of ONS's businesses surveys, STES are stratified by industry, as well as by size of business. Stratification gives greater control over coverage and makes more efficient use of the sample. The new industrial strata based on SIC 2007 have been chosen after consultation with users and consideration of quality, disclosure and business compliance issues. They reflect a balance of user requirements, survey resources and employment levels and trends. The most detailed breakdown of EJ by industry is available in Table 6.05 of Economic \& Labour Market Review $(E L M R)^{1}$, which is on the new SIC 2007 basis from the August 2010 edition.

The size bands have also been reviewed in the context of each industry. In turn these changes have necessitated a re-allocation of the sample, ensuring most efficient use of the sample to meet user needs. Table 1 shows a reduction of 104,000 (52 per cent) to STES employment questionnaires per annum, reducing both the administrative burden on businesses and operational cost for government.

The gender and full/part-time employment variables are still collected. The decision to retain these variables was made following consultation with users. These variables are weighted using the same estimation weights calculated for the employment totals.

\section{New estimation methods for the Short Term Employer Surveys}

ONS has taken the opportunity provided by the move to SIC 2007 to change the 
Table 1

\section{Restructuring the Short Term Employer Surveys ${ }^{1,2}$}

\begin{tabular}{|c|c|c|c|c|c|}
\hline \multicolumn{3}{|c|}{ To 2009 Q4 } & \multicolumn{3}{|c|}{ From 2010 Q1 } \\
\hline Survey & Variables & Sample size & Survey & Variables & Sample size \\
\hline MIDSS & $\begin{array}{l}\text { monthly t/o \& } \\
\text { quarterly emp }\end{array}$ & $\begin{array}{l}23,000 \mathrm{t} / 0 \\
17,000 \text { emp sub-sample }\end{array}$ & \multirow{2}{*}{ MBS } & \multirow{2}{*}{$\begin{array}{l}\text { monthly t/o \& } \\
\text { quarterly emp }\end{array}$} & \multirow{2}{*}{$\begin{array}{l}30,000 \mathrm{t} / 0 \\
17,000 \mathrm{emp} \text { sub-sample }\end{array}$} \\
\hline \multirow[t]{2}{*}{ MPI } & $\begin{array}{l}\text { monthly t/o \& } \\
\text { monthly emp }\end{array}$ & 7,500 & & & \\
\hline & monthly emp only & 200 & \multirow{2}{*}{ QBS } & \multirow{2}{*}{ quarterly emp only } & \multirow{2}{*}{5,000} \\
\hline QIDSS & Quarterly emp only & 5,000 & & & \\
\hline RSI & $\begin{array}{l}\text { monthly t/o \& } \\
\text { quarterly emp }\end{array}$ & 5,000 & RSI & $\begin{array}{l}\text { monthly t/o \& } \\
\text { quarterly emp }\end{array}$ & $\begin{array}{l}5,000 \mathrm{t} / \mathrm{o} \\
2,100 \mathrm{emp} \text { sub-sample }\end{array}$ \\
\hline \multicolumn{2}{|c|}{$\begin{array}{l}\text { Total employment sample } \\
\text { Quarter months } \\
\text { Non-quarter months } \\
\text { Annual total }\end{array}$} & $\begin{array}{l}34,700 \\
7,700 \\
200,400\end{array}$ & \multicolumn{2}{|c|}{$\begin{array}{l}\text { Total employment sample } \\
\text { Quarter months } \\
\text { Non-quarter months } \\
\text { Annual total }\end{array}$} & $\begin{array}{l}24,100 \\
0 \\
96,400\end{array}$ \\
\hline
\end{tabular}

\section{Notes:}

Source: Office for National Statistics

$1 \mathrm{t} / \mathrm{o}=$ turnover and refers to all output variables.

$2 \mathrm{emp}=$ employment variables.

STES estimation methods. This fulfils long-standing recommendations from the National Statistics Quality Review of Employment and Jobs Statistics (2006) and the Review of Workforce Jobs Benchmarking (2007). The new methods have been implemented from 2008 Q3 coinciding with the use of domain estimation described before. This avoids an additional discontinuity and makes further use of the domain estimation systems developed for the transition to SIC 2007.

The existing matched-pairs estimator has been replaced by a point-in-time ratio estimator, ONS's standard method. This change is aimed at removing the apparent bias caused by the matched-pairs method. The matched-pairs method tends to underestimate the change over time, as it excludes the births and deaths of businesses in the sample. In essence, only those businesses sampled in two consecutive periods are used to produce estimates of change. This bias causes large revisions when the STES series are benchmarked retrospectively to $\mathrm{ABI} 1$ estimates. $\mathrm{ABI} 1$ selects a larger sample and also uses a pointin-time ratio estimator. The new estimator includes all sampled businesses in each and every period, which reduces the bias over-time. The trade-off is an increase in volatility caused by the inclusion of the rotated part of the sample for small and medium sized businesses. Sample rotation spreads the administrative burden; ensuring businesses are selected for a limited number of periods.

The method for apportioning reporting units by their registered local units (LUs) has also changed. Businesses are sampled from the IDBR on a reporting unit (RU) basis. An RU is a register construct. Larger enterprises are often split into a number of RUs that report for different LUs. For example, an enterprise might have RUs for different regions or activities, each reporting for the local units, such as retail outlets or factories, in their region or imputed data for non-responders) for the using the ratio of LU to RU employment data from the IDBR. This process produces more refined employment estimates by region and by industry. The local unit estimates are weighted to represent nonsampled units (again using data from the IDBR) and aggregated by industry and region. The LU apportionment now occurs at an earlier stage and so the calibration weights are calculated on an LU basis as opposed to an RU basis.

EJ estimates by Government Office Region (GOR) are now produced directly. Previously, EJ estimates were produced on the old Standard Statistical Regional basis (SSR) and then converted to GOR at the aggregate level using GOR to SSR ratios from ABI1. Most regions have the same geographic boundaries under GOR and SSR. More information on GOR and SSR is available at www.statistics.gov.uk/ geography/gor.asp. The SSR series are being discontinued so EJ series will now be available by GOR only, starting in 1981 Q3 .

\section{Benchmarking GB Employee Jobs to the Annual Business Inquiry (ABI1)}

Benchmarking is an annual process to align the quarterly GB EJ series to the latest estimates from ABI1. ABI1 is based on a sample of approximately 80,000 reporting units, a much larger sample than STES, and so generally produces more accurate and detailed estimates. ABI1 estimates refer activity. The returned employment data (or sampled RUs are apportioned by their LUs to Q4 in each year up to 2005 and Q3 in subsequent years.

The benchmarking process was more intricate this year due to the move to SIC 2007 and other developments described in this article. In December 2009 ONS released ABI1 estimates for 2007 (revised) and 2008 (provisional) on both a SIC 2003 and a SIC 2007 basis. 2008 was the first year the ABI1 was selected and weighted on a SIC 2007 basis, but dual coding enabled estimates to be aggregated on both a SIC 2003 and a SIC 2007 basis. 2007 ABI1 was selected and weighted on a SIC 2003 basis, but again dual coding enabled estimates to be aggregated on both bases. The quarterly EJ series were benchmarked to SIC 2003 ABI1 estimates up to 2007 (provisional), before converting them from SIC 2003 to SIC 2007 (as explained before). The converted SIC 2007 series were then benchmarked to the SIC 2007 ABI1 estimates for 2007 (revised) and 2008 (provisional).

For some industries the SIC 2007 ABI1 estimates for 2007 (revised) have not been used as benchmarks due to the following two reasons:

- where analysis has shown significant misclassifications of businesses on SIC 2007 within ABI1 2007 estimates, which stem from the IDBR at a time when the dual codes were relatively new and unstable

- where the public sector source is already ONS's definitive Public Sector Employment (PSE) series. The public and private sector series were aggregated before the conversion from SIC 2003 to SIC 2007 and so the private sector components alone could not be benchmarked to SIC 2007 ABI1 estimates after the conversion process. Benchmarking the converted series to a combined public and private benchmark would have changed the public sector source from PSE to ABI1, a backwards step that would have caused discontinuities. Further information on PSE inputs are provided in a later section of this article

\section{Removal of benchmarking discontinuities from GB Employee Jobs}

ONS has taken the opportunity to remove discontinuities caused by previous benchmarking exercises and also remove the need for carrying forward various benchmarking adjustments each year.

Developments to ABI1 sources and methods in 2006 caused a discontinuity 
between 2005 Q4 and 2006 Q3. The discontinuity was passed on to quarterly EJ estimates through the benchmarking process (Barford 2007). In December 2009 ONS released analysis and estimates of this discontinuity (Gough 2009). This has enabled the discontinuity to be removed from quarterly EJ series within WFJ. The detailed level series have been adjusted prior to 2006 Q3 to reflect the revised ABI1 methods. In total 2005 Q4 has been reduced by approximately 203,000 jobs. The adjustments were wedged forwards to 2006 Q3 and backwards to 1996 Q1, the start of the most detailed EJ series.

In 2005 the IDBR increased the scope of the survey universe by including 'unmatched PAYE units in VAT exempt industries. This added around 0.3 per cent to the registered employment, largely concentrated in health and education. The published ABI1 2005 estimates included these additional units, but their effect was removed from the ABI1 estimates used for benchmarking (in total 77,000 jobs) to avoid a discontinuity in WFJ. A downward adjustment of 19,000 jobs was also made to the ABI1 2005 benchmarks to remove a discontinuity caused by the misreporting of employment agencies (SIC 2003 division 74.5). Similarly in 2004, a downward adjustment of 16,000 jobs was made in health (SIC 2003 division 85). These benchmark adjustments have been carried forward each year. To avoid this process in future and to improve coherence between published WFJ and ABI1 estimates, ONS has now removed these forward adjustments and instead applied adjustments backwards, wedging the discontinuities out of the back series to 1996 Q1.

A downward adjustment of 13,000 in 2006 Q3 has also been made in retail (SIC 2004 division 45) due to misreporting in 2006 ABI1 estimates. This has been wedged back to the previous benchmark in 2005 Q4.

These adjustments had to be made to the SIC 2003 series, before the conversion to SIC 2007 described before. Figure 1 illustrates these revisions to total GB Employee Jobs series (not seasonally adjusted). Figure 2 compares the previously published and revised UK Employee Jobs series (not seasonally adjusted) from 1996 Q1.

\section{Inputs from Public Sector Employment (PSE)}

ONS's PSE estimates are deemed to be the definitive source for public sector

\section{Figure 1}

\section{Revisions to NSA Employee Jobs due to benchmarking adjustments}

\section{Great Britain}

Thousands, not seasonally adjusted

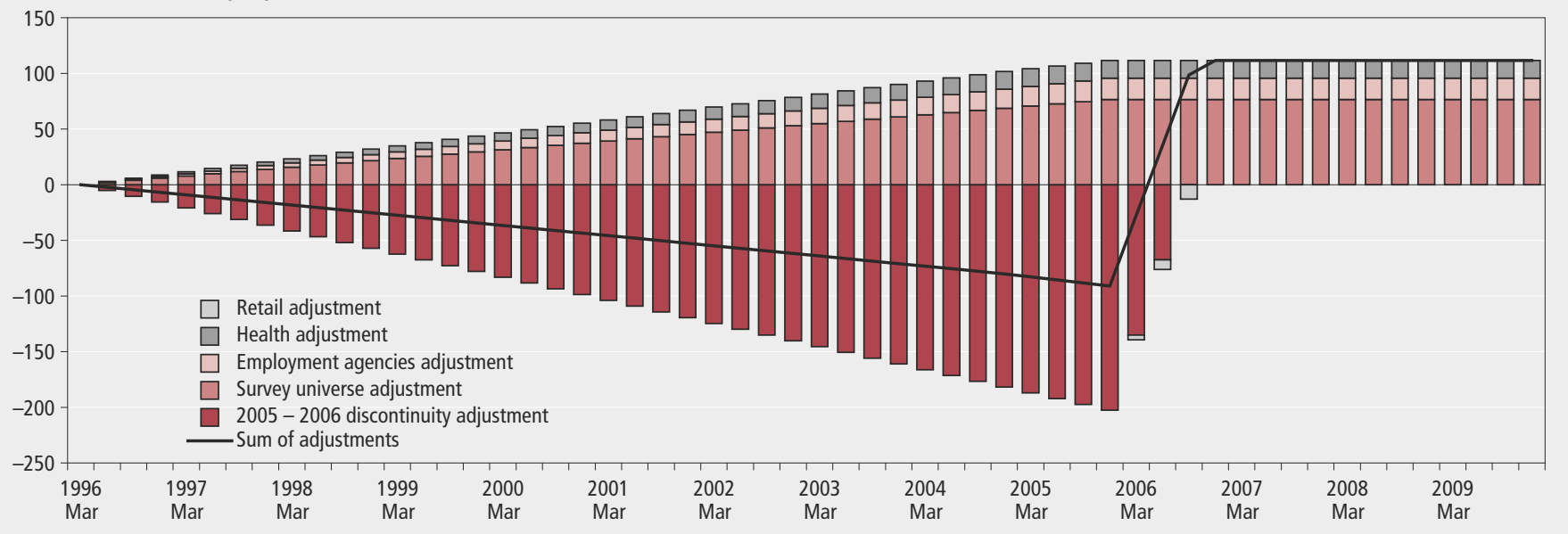

Source: Employee Jobs

Figure 2

\section{Previously published versus revised NSA Employee Jobs}

\section{United Kingdom}

Thousands, not seasonally adjusted

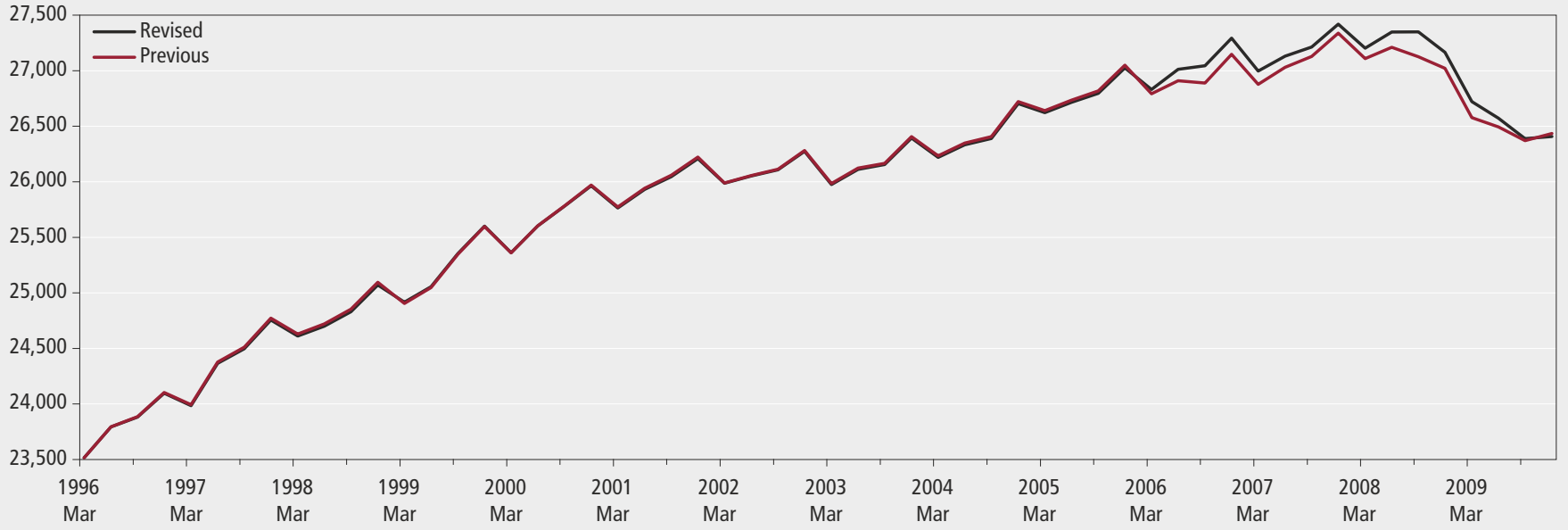

Source: Employee Jobs 
employment. The PSE sources form a census of the public sector as defined by National Accounts definitions. The bulk of PSE estimates are contained within public administration and defence, education, health and social work (SIC 2003 sections L, $\mathrm{M}$ and $\mathrm{N}$ or SIC 2007 sections $\mathrm{O}, \mathrm{P}$ and Q). These PSE series, along with those for post and telecommunications and recreation, cultural and sporting activities (SIC 2003 divisions 64 and 92), were integrated in to the WFJ dataset in 2005 (see Barford 2005). For all other industries the public sector was covered by benchmarking the quarterly series to ABIl estimates for both the public and private sectors.

PSE series have now been produced with a more detailed breakdown by industry (SIC 2007) and by region (GOR) from 2008 Q1. This has enabled PSE to be used as the source of GB public sector EJ for most industries within WFJ from 2008 Q4. This coincides with the start of the new GB private sector EJ series produced using the STES domain estimation methods described above, avoiding another discontinuity. The quarterly GB private sector EJ series are benchmarked to private sector ABI1 estimates for 2008 Q3 and then aggregated with the PSE series. In effect, the source of Public Sector Employment within WFJ has switched from ABI1 in 2008 Q3 to PSE in 2008 Q4 for those industries that were not previously covered by PSE. The effect of this is small because the estimates from PSE and ABI1 are similar.

For agriculture (section $\mathrm{A}$ ) and construction (section F, not including 41.1) the LFS remains the WFJ source of quarterly EJ for both the public and private sectors and so these series are still benchmarked to ABI1 estimates for both public and private sectors.

Her Majesty's Forces (HMF) also feeds WFJ from the PSE dataset, which in turn come from Defence Analytical Services and Advice (DASA). The HMF series now feed WFJ by region from 1996 Q1, enabling regional WFJ series to be produced. Previously the regional WFJ series excluded HMF and were termed Civilian WFJ. HMF based overseas are included in the UK estimates and so the sum of the regional WFJ estimates is slightly less than UK WFJ.

\section{Inputs from the Labour Force Survey (LFS)}

The LFS provides WFJ with SEJ series, the industry breakdown for the GST series and EJ series for agriculture and construction.

The LFS inputs have been revised as follows:
- the industry classification has changed from SIC 1992 (similar to SIC 2003) to SIC 2007. LFS variables were coded on the SIC 2007 basis from the start of 2009. Prior to 2009, weighted LFS estimates on the SIC 1992 basis have been mapped to SIC 2007 and reaggregated

- the LFS is a monthly survey from which series of rolling three-month averages are produced. Ideally the averages centred on the last month of each quarter should be used for quarterly WFJ, for example February to April for Q1 and May to July for Q2 (rolling quarters). Previously the SEJ totals were based on rolling quarters. However the industry and regional breakdowns for SEJ were produced by apportioning the total series using industry and regional series based on calendar quarters (January to March for Q1). The GST series and the EJ series for agriculture and construction were also based on calendar quarters. This has now changed so that all of the LFS inputs to WFJ are based on rolling quarters from $2006 \mathrm{Q} 2$. Prior to 2006 Q2 the LFS series based on SIC 2007 are only available for calendar quarters. The calendar quarters have been interpolated to produce monthly series, from which the rolling quarters are used for WFJ inputs

- the LFS inputs for SEJ and GST now feed WJF at a more detailed level, that is, by industry division by region. Previously, the LFS series were input by industry and separately by region, but not industry by region. This enables WFJ by region by industry series to be produced for the first time, and so the regional statistical bulletin tables are now produced with the same breakdowns and layouts as the national

\section{Revisions to other sources}

Small revisions have been taken on from administrative sources for Government Supported Trainees. Northern Ireland inputs from the Department of Enterprise, Trade and Investment in Northern Ireland (DETI NI) have also been revised slightly and are now based on SIC 2007.

\section{Seasonal adjustment review}

Seasonal adjustment is the process of identifying and removing the seasonal components from a series to leave the underlying trend and irregular components. The revised WFJ series have undergone a seasonal adjustment review causing revisions back to 1978 Q2.

The new WFJ system seasonally adjusts using X12 ARIMA. This is superior to X11 ARIMA which was used in the previous system.

The level at which seasonal adjustment is performed has also changed. Previously, only the following series were seasonally adjusted:

- GB and UK WFJ by component (EJ, SEJ, GST and HMF) by gender

- UK WFJ by broad section groups by gender

- UK EJ by broad section groups by gender

- EJ by region by gender

Constraining processes were used to ensure the WFJ components and broad sections added to the same total. The new system seasonally adjusts WFJ components by sections by regions and then aggregates the series through these three hierarchical dimensions. This bottom-up approach maintains additivity throughout the seasonally adjusted dataset without the need for constraining. It also provides more seasonally adjusted series by industry and by region and enables the regional statistical bulletin tables to be produced with the same breakdowns and layouts as the national. However, this approach increases the number of seasonal adjustment parameters to review each year. To counter this issue, the gender series are no longer being adjusted, although the non-seasonally adjusted series are still available to users.

Figure 3 compares the previously published and revised seasonally adjusted UK Workforce Jobs series from 1996 Q1.

\section{Changes to publication tables}

ONS has made changes to the WFJ publication tables. The move to SIC 2007 required changes to reflect the new industry breakdown. At the same time ONS took the opportunity to implement other changes given the availability of data from the new WFJ systems, feedback from users and an internal review of all Labour Market statistical outputs.

The WFJ tables within UK Labour Market Statistical Bulletin have changed from the July 2010 edition as follows:

- Table 5(1) Workforce Jobs by component is now labelled Table 5

- Table 5(2) Workforce Jobs by industry is now labelled Table 6 . The nine broad 


\section{Figure 3}

\section{Previously published versus revised SA Workforce Jobs}

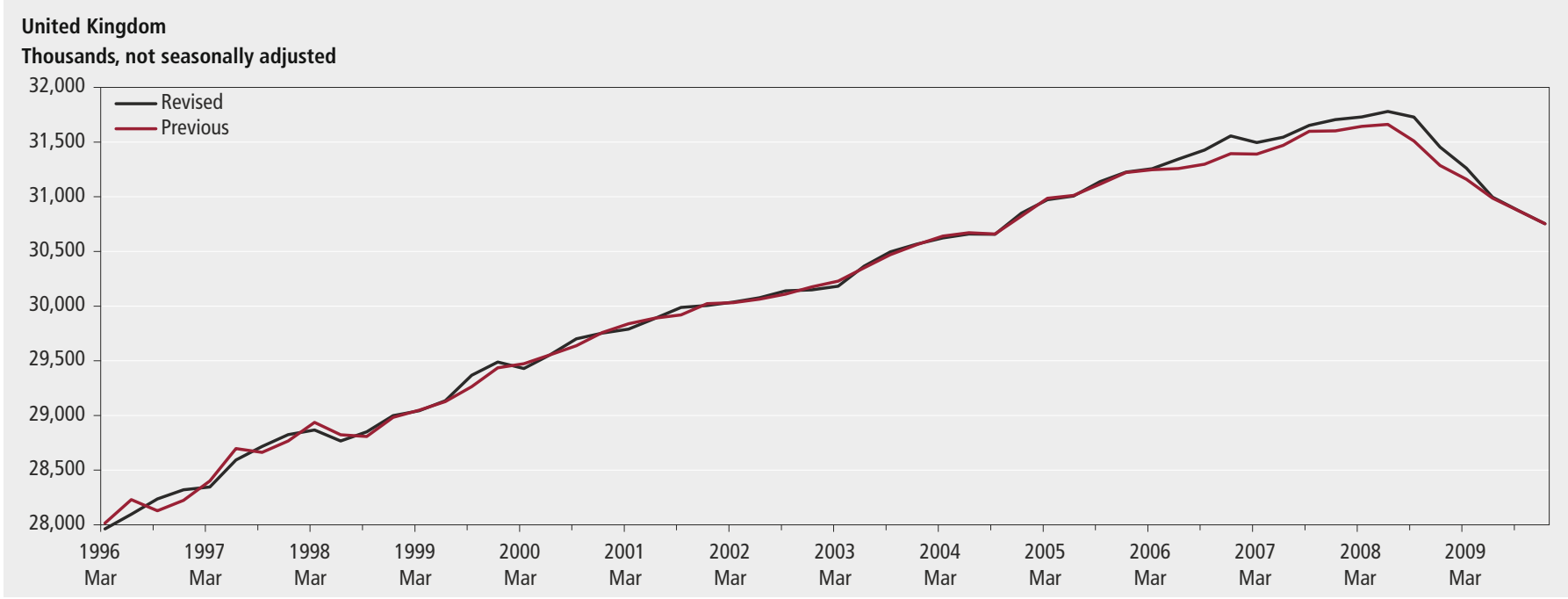

Source: Workforce Jobs

section groups on SIC 2003 have been replaced by 19 sections on SIC 2007. The gender breakdown has been removed given the additional industry detail and changes to the level of seasonal adjustment

- Table 6 Production industries Employee Jobs has been discontinued due to the change in frequency of the series from monthly to quarterly, which brings production in line with all others

Tables 4 and 5 of the Regional Labour Market Statistical Bulletins now have exactly the same breakdowns and layout as Table 5 and 6 of the UK Labour Market Statistical Bulletin.

Tables 2.05 and 2.06 in Economic \& Labour Market Review (ELMR) provide longer time series for Table 5 and 6 of the UK Labour Market Statistical Bulletin. ELMR Tables 6.04, 6.05 and 6.06 provide more detail by region, industry, gender and full / part-time status. Their content and layout has changed to provide further detail and longer time series. These changes took effect from the August 2010 edition of ELMR.

WFJ data is also published on the Nomis website at www.nomisweb.co.uk. Series are now available for WFJ components by regions by industry sections; not seasonally adjusted and seasonally adjusted. Gender and full / part-time variables are also available; not seasonally adjusted.

Annex B provides a list of WFJ publication tables and their detail.

\section{Notes}

1. Monthly updates of labour market data are available from the Economic \& Labour Market Review pages on the ONS website at:

www.statistics.gov.uk/elmr

\section{ABBREVIATIONS}

ABI1 Annual Business Inquiry

EJ Employee Jobs

GOR Government Office Region

GST Government-supported Trainees

HMF Her Majesty's Forces

IDBR Inter-Departmental Business Register

LFS Labour Force Survey

LUs Local Units

MBS Monthly Business Survey

MIDSS Monthly Inquiry into the Distribution and Service Sector

MPI Monthly Production Inquiry

NSA Not Seasonally Adjusted

PAYE Pay As You Earn

PSE Public Sector Employment

QBS Quarterly Business Survey

QIDSS Quarterly Inquiry in the Distribution and Service Sector

RSI Retail Sales Inquiry

RU Reporting Unit

SA Seasonally Adjusted

SEJ Self-employment Jobs

SIC Standard Industrial Classification

SSR Standard Statistical Region

STES Short-Term Employer Surveys

WFJ Workforce Jobs

\section{CONTACT}

지 elmr@ons.gsi.gov.uk

\section{REFERENCES}

National Statistics Quality Review Series Report No. 44: Employment and Jobs Statistics (2006). Available at: www.ons.gov.uk/about-statistics/ methodology-and-quality/quality/nat-statsqual-revs/qual-revs-by-theme/labour-market/ index.html

Review of Workforce Jobs Benchmarking (2007) Available at:

www.statistics.gov.uk/StatBase/Product. asp?vlnk=9765

Barford N (2005) 'Revisions to Workforce Jobs, December 2005'. Available at: www.statistics.gov.uk/StatBase/Product. asp? vlnk=9765

Barford N (2007) 'Revisions to Workforce Jobs, December 2007'. , Economic \& Labour Market Review, Vol 2 No 3. Available at: www.statistics.gov.uk/StatBase/Product. asp?vlnk=9765

Gough J (2009) 'Discontinuity analysis affecting the $2006 \mathrm{ABI}$ employee estimates', Economic \& Labour Market Review, Vol 3 No 12. Available at:

www.statistics.gov.uk/CCl/article. asp? ID $=2343$

Hughes J C, James G, Evans A and Prestwood D (2009) 'Implementation of Standard Industrial Classification 2007: December 2009 update', Economic \& Labour Market Review, Vol 3 No 12. Available at: www.statistics.gov.uk/CCl/article. asp? ID =2341 
ANNEX A

Table A 1

\section{Workforce Jobs sources}

\begin{tabular}{|c|c|c|}
\hline \multicolumn{2}{|l|}{ Component } & Source \\
\hline \multicolumn{3}{|l|}{ Employee Jobs } \\
\hline \multirow{5}{*}{ Great Britain } & Private Sector & Short Term Employer Surveys (STES), benchmarked to Annual Business Inquiry (ABI1) \\
\hline & Public Sector & $\begin{array}{l}\text { Public Sector Employment (PSE) from Quarterly Public Sector Employment Surveys (QPSES) and administrative sources } \\
\text { from other government departments and devolved administrations }\end{array}$ \\
\hline & Agriculture & Labour Force Survey (LFS), benchmarked to Annual Business Inquiry (ABI1) \\
\hline & Construction & Labour Force Survey (LFS), benchmarked to Annual Business Inquiry (ABI1) \\
\hline & Air transport & Civil Aviation Authority (CAA), benchmarked to Annual Business Inquiry (ABI1) \\
\hline \multicolumn{2}{|l|}{ Northern Ireland } & Department of Enterprise, Trade and Investment Northern Ireland (DETI NI) \\
\hline Self-Employed Jobs & & Labour Force Survey (LFS) - main and second jobs by industry by region \\
\hline \multicolumn{3}{|c|}{ Government Supported Trainees } \\
\hline \multicolumn{2}{|l|}{ England } & Department for Business, Innovation and Skills (BIS), split by industry using LFS \\
\hline \multicolumn{2}{|l|}{ Wales } & Welsh Assembly Government (WAG), split by industry using LFS \\
\hline \multicolumn{2}{|l|}{ Scotland } & Scottish Government (SG), split by industry using LFS \\
\hline \multicolumn{2}{|l|}{ Northern Ireland } & Department of Enterprise, Trade and Investment Northern Ireland (DETI NI), split by industry using LFS \\
\hline \multicolumn{2}{|l|}{ Her Majesty's Forces } & Defence Analytical Services and Advice (DASA) \\
\hline
\end{tabular}

Source: Office for National Statistics

ANNEX B

Table B1

Workforce Jobs publication tables

\begin{tabular}{|c|c|c|c|c|c|c|c|c|c|}
\hline Publication & Release update & Table & Component & $\begin{array}{l}\text { Region } \\
\text { (lowest) }\end{array}$ & \begin{tabular}{|l} 
Industry \\
(lowest)
\end{tabular} & Employment splits & $\begin{array}{l}\text { Seasonally } \\
\text { Adjusted }\end{array}$ & \begin{tabular}{|l|} 
Start \\
date / \\
Time \\
span
\end{tabular} & Periodicity \\
\hline \multirow{2}{*}{$\begin{array}{l}\text { UK Labour } \\
\text { Market } \\
\text { Statistical } \\
\text { Bulletin }\end{array}$} & \multirow[b]{2}{*}{ Quarterly } & 5 Workforce Jobs & WFJ, EJ, SEJ, HMF, GST & UK & A-S & Total & SA & 2 years & Quarterly \\
\hline & & 6 Workforce Jobs by industry & WFJ & UK & Sections & Total & SA & 2 years & Quarterly \\
\hline \multirow{3}{*}{$\begin{array}{l}\text { Regional } \\
\text { Labour Market } \\
\text { Statistical } \\
\text { Bulletins }\end{array}$} & \multirow{3}{*}{ Quarterly } & 4 Workforce Jobs & WFJ, EJ, SEJ, HMF, GST & GOR & A-S & Total & SA & 2 years & Quarterly \\
\hline & & 5 Workforce Jobs by industry & WFJ & GOR & Sections & Total & SA & 2 years & Quarterly \\
\hline & & Regional summary $18(2)$ & WFJ & GOR & A-S & Total & SA & 2 quarters & Quarterly \\
\hline \multirow{5}{*}{$\begin{array}{l}\text { Economic \& } \\
\text { Labour Market } \\
\text { Review (ELMR) }\end{array}$} & \multirow{5}{*}{ Quarterly } & $\begin{array}{l}6.04 \text { Workforce Jobs by } \\
\text { industry }\end{array}$ & WFJ, EJ, SEJ & UK & Sections & Total & SA, NSA & 1996Q1 & Quarterly \\
\hline & & $\begin{array}{l}6.05 \text { Employee Jobs by } \\
\text { industry }\end{array}$ & EJ & UK, GB & Lowest level & Total, MFT, MPT, FFT, FPT & NSA & 1996 Q1 & Quarterly \\
\hline & & $\begin{array}{l}6.06 \text { Workforce Jobs by } \\
\text { region and industry }\end{array}$ & WFJ & GOR & Sections & Total & SA & 1996 Q1 & Quarterly \\
\hline & & 2.05 Workforce Jobs & WFJ, EJ, SEJ, HMF, GST & UK & A-S & Total & SA & 1978 Q2 & Quarterly \\
\hline & & $\begin{array}{l}\begin{array}{l}2.06 \text { Workforce Jobs by } \\
\text { industry }\end{array} \\
\end{array}$ & WFJ & UK & Sections & Total & SA & 1978 Q2 & Quarterly \\
\hline \multirow{3}{*}{ Statbase } & \multirow{3}{*}{ Quarterly } & $\begin{array}{l}\text { LMS1 Employee Jobs by } \\
\text { industry }\end{array}$ & EJ & UK & Sections & Total & SA & 1978 Q2 & Quarterly \\
\hline & & LMS4 Workforce Jobs & WFJ, EJ, SEJ, HMF, GST & UK & A-S & Total & SA & 1959 & Quarterly \\
\hline & & $\begin{array}{l}\text { LMS5 Workforce Jobs by } \\
\text { industry }\end{array}$ & WFJ & UK & Sections & Total & SA & 1978 Q2 & Quarterly \\
\hline \multirow{2}{*}{ Nomis } & \multirow{2}{*}{ Quarterly } & $\begin{array}{l}\text { Workforce Jobs by industry } \\
\text { SA }\end{array}$ & WFJ, EJ, SEJ, HMF, GST & GOR & Sections & Total & SA & 1981 Q3 & Quarterly \\
\hline & & $\begin{array}{l}\text { Workforce Jobs by industry } \\
\text { NSA }\end{array}$ & WFJ, EJ, SEJ, HMF, GST & GOR & Sections & Total, MFT, MPT, FFT, FPT & NSA & 1981 Q3 & Quarterly \\
\hline \multirow[b]{2}{*}{ Monthly Digest } & \multirow[b]{2}{*}{ Quarterly } & 3.2 Workforce Jobs & WFJ, EJ, SEJ, HMF, GST & UK & A-S & Total & SA & 1996 Q1 & Quarterly \\
\hline & & $\begin{array}{l}3.3 \text { Workforce Jobs by } \\
\text { industry }\end{array}$ & WFJ & UK & Sections & Total & SA & 1996 Q1 & Quarterly \\
\hline Social Trends ${ }^{1}$ & Annually (June) & $\begin{array}{l}\text { D.08 Employee Jobs by } \\
\text { industry }\end{array}$ & EJ & UK & Section groups & Total & NSA & 30 years & Annual (Q2) \\
\hline Regional Trends' ${ }^{1}$ & Annually (June) & $\begin{array}{l}\text { 9.4 Industrial composition of } \\
\text { Employee Jobs } \\
\end{array}$ & EJ & GOR & Section groups & Total & NSA & 10 years & Annual (Q2) \\
\hline \multirow{4}{*}{ Annual Abstract ${ }^{1}$} & \multirow{4}{*}{ Annually (July) } & \multirow{2}{*}{$\begin{array}{l}\text { 7.4 Distribution of the } \\
\text { workforce by sex }\end{array}$} & WFJ, SEJ, HMF & UK, GB & $\mathrm{A}-\mathrm{O}$ & Total, Male, Female & SA & 11 years & Annual (Q2) \\
\hline & & & EJ & & Section groups & Total, Male, Female & SA & 12 years & Annual (Q2) \\
\hline & & \multirow{2}{*}{$\begin{array}{l}7.5 \text { Employee Jobs by } \\
\text { industry }\end{array}$} & EJ & UK & Sections & Total & NSA & 5 years & Annual (Q2) \\
\hline & & & & GB & Lowest level & Total & NSA & 5 years & Annual (Q2) \\
\hline
\end{tabular}

Notes:

Source: Office for National Statistics

1 Subject to review under SIC 2007 